GLOBAL JOURNAL OF MATHEMATICAL SCIENCES VOL. 12, 2013: 31-38

COPYRIGHTC BACHUDO SCIENCE CO. LTD PRINTED IN NIGERIA ISSN 1596-6208

\title{
APPROXIMATION OF COMMON FIXED POINTS OF A FINITE FAMILY OF $\phi-$ DEMICONTRACTIVE MAPPINGS BY AN IMPLICIT ITERATION METHOD.
}

DONATUS I. IGBOKWE AND UNWANA E. UDOFIA

\section{ABSTRACT}

We prove that the Implicit Iteration process of Xu and Ori (2001) converges strongly to the commonfixed pointsof a finite family of $\phi$-demicontractive mappings in real Hilbertand Banachspaces. Our results extend the results of Osilike (2004a) from strictly pseudocontractive maps to the much more general $\phi$-demicontractive maps;complement and generalize several others in the literature.

KEY WORDS AND PHRASES: $\phi$-Demicontractive Maps, Implicit Iteration Process, Fixed Points,Strong Convergence.

\section{INTRODUCTION AND PRELIMINARIES}

Let $\mathrm{E}$ be a real Banach space. Let $J$ denote the normalized duality mapping from $\mathrm{E}$ into $2^{\mathrm{E}^{*}}$ given by $J(x)=\left\{f \in \mathrm{E}^{*}:\langle x, f\rangle=\|x\|^{2} ;\|x\|^{2}=\|f\|^{2}\right\}$, where $E^{*}$ denotes the dual space of $E$ and $\langle$,$\rangle denotes the generalized$ duality pairing. If $E^{*}$ is strictly convex, then $J$ is single-valued. In the sequel, we shall denote single-valued duality mapping by $j$.

Let $K$ be a nonempty subset of $E$. A mapping $T: K \rightarrow K$ is said to be demicontractive (see, for example,Hicks and Kubicek, (1979).) if $\mathrm{F}(\mathrm{T})=\{x \in K: T x=x\} \neq \phi$ and for all $x \in K$ and $p \in F(T)$, there exists $j(x-p) \in J(x-p)$ and a constant $\lambda>0$ such that

$$
\langle x-T x, j(x-p)\rangle \geq \lambda\|x-T x\|^{2} \text {. }
$$

In Hilbert spaces equation(1) is equivalent to:

$$
\|T x-p\|^{2} \geq\|x-p\|^{2}+(1-2 \lambda)\|x-T x\|^{2}
$$

and we may assume that $1-2 \lambda=k>0$.

Furthermore, $T$ is $L$-Lipschitzian if there exists a constant $L>0$ such that $\|T x-T y\| \leq L\|x-y\|$ for all $x, y \in K$.

The class of demicontractive maps was first introduced in Hilbert space by Hicks and Kubicek (1979). Maruster (1977) also considered this class of mappings using equation (1) which he referred to as condition $(A)$.

A mapping $T: K \rightarrow K$ is called strictlypseudocontractive in the terminology of Browder and Petryshyn (1967) if for all $x, y \in K \quad$ and $j(x-y) \in J(x-y)$ there exists $\lambda>0$ such that $\langle T x-T y, j(x-y)\rangle \leq\|x-y\|^{2}-\lambda\|x-y-(T x-T y)\|^{2}$. A strictly pseudocontraction with a nonempty fixed point set $F(T)$ is demicontractive. An example of a demicontractive map which is not strictly pseudocontractive is given by Hicks and Kubicek (1979).

A mapping $T: K \rightarrow K$ is said to be $\phi$-demicontractive (Isiogugu, 2005) if $F(T) \neq \phi$ and there exists a strictly increasing continuous function $\phi:[0, \infty) \rightarrow[0, \infty)$ with $\phi(0)=0$ such that

$$
\begin{aligned}
& \langle x-T x, j(x-p)\rangle \geq \phi(\|x-T x\|), \\
& \forall x \in D(T), p \in F(T) \operatorname{andj}(x-p) \in J(x-p) .
\end{aligned}
$$


This class of maps was first studied in arbitrary real Banach space by Isiogugu (2005).

Observe that in real Hilbert spaces, $j$ is the identity and for all $x \in K$ and $p \in F(T)$, we obtain from equation(3) that

$\|T x-T p\|^{2}=\|x-p-[(I-T) x-(I-T) p]\|^{2}$

$$
=\|T x-p\|^{2}-2\langle(I-T) x-(I-T) p, x-p\rangle+\|(I-T) x-(I-T) p\|^{2} \leq\|\mathrm{x}-\mathrm{p}\|^{2}+\| \mathrm{x}-\left.\mathrm{Tx}\right|^{2}-
$$

$2 \phi(\|x-T x\|$.

Hence it follows that in a real Hilbert space, equation (3) is equivalent to equation (4). Every demicontractive map is $\phi$ - demicontractive with $\phi:[0, \infty) \rightarrow[0, \infty)$ given by $\phi(t)=\lambda t^{2}$. The following example (Isiogugu, 2005) shows that the class of demicontrative maps is a proper subclass of $\phi$-demicontractive maps:

Let $\Re$ denote the reals with the usual norm and let $K=(-\infty, 1)$. Define $T: K \rightarrow K$ by

$$
T x=\left\{\begin{array}{cc}
\frac{x}{1-x} & ,-\infty<x \leq 0 \\
\frac{x}{x-1} & , \quad 0 \leq x<1
\end{array}\right.
$$

Then $F(T)=\{0\}$ and if $p=0$, then $|T x-T p|=\frac{|x|}{1-x} \leq|x-p|$

Thus, $\quad|T x-T p|^{2}=|x-p|^{2}-2\langle x-T x, x-p\rangle+|x-T x|^{2} \leq|x-p|^{2}$

so that

$$
\langle x-T x, x-p\rangle \geq \frac{1}{2}|x-T x|^{2} \geq \frac{|x-T x|^{2}}{2+|x-T x|},
$$

for all $x \in(-\infty, 0]$ and $p \in F(T)$.

For every $x \in[0,1)$, we have $T x=\frac{x}{x-1}$ and $x-T x=\frac{x(2-x)}{1-x}=|x-T x|$.

Thus, $2+|x-T x|=\frac{2-x^{2}}{1-x} \quad$ and $\quad \frac{|x-T x|}{2+|x-T x|}=\frac{x(2-x)}{2-x^{2}} \leq x=|x|$

For $p=0 \in F(T)=\{0\}$, we have

$$
\langle x-T x, x-p\rangle=x(x-T x)=|x||x-T x| \geq \frac{|x-T x|^{2}}{2+|x-T x|} .
$$

Equations (5) and (6) now imply that

$$
\langle x-T x, x-p\rangle \geq \frac{|x-T x|^{2}}{2+|x-T x|}, \forall x \in(-\infty, 1)
$$

and $\forall p \in F(T)$.

It follows that $\langle x-T x, x-p\rangle \geq \phi(|x-T x|)$ where $\phi:[0, \infty) \rightarrow[0, \infty)$ is

given by $\quad \phi(t)=\frac{t^{2}}{2+t}$. Clearly, $\phi$ is continuous, strictly increasing and $\phi(0)=0$. Hence $T$ is $\phi$ demicontractive.Given any $L>0$, if we choose $x \in\left(1-\frac{1}{L}, 1\right)$, then $\quad|T x-p|=\frac{|x|}{1-x}=\frac{1}{1-x}|x-p|>L|x-p|$. 
Since every demicontractive mapping $T: D(T) \subseteq \mathrm{E} \rightarrow \mathrm{E}$ satisfies

||$T x-p \| \leq L|| x-p||, \forall x \in D(T), p \in F(T)$ and for some $L>0$ ( see for example Chidume and Nnoli, 2002; Hicks and Kubicek, 1979; Maruster,1977; Osilike and Udomene, 2001), it follows that $T$ is not demicontractive. Isiogugu (2005), proved the convergence of the Mann (1953) iteration scheme to the fixed points of $\phi-$ demicontractive maps. Specifically, the author proved the following theorem:

Theorem 1.1 (Isiogugu (2005)) Let $E$ be a real Banach space and let $K$ be a nonempty closed convex subset of $E$ . Let $T: K \longrightarrow K$ be Lipschitz $\phi$-demicontractive map with Lipschitzconstant $L$. Let $\left\{\alpha_{\bar{n}}\right\}$ be a real sequence satisfying the conditions:

$$
\text { (i) } 0<\alpha_{n}<1_{\text {(ii) }} \sum_{n=1}^{\infty} \alpha_{n}=\infty \text { (iii) } \sum_{n=1}^{\infty} \alpha_{n}^{2}<\infty
$$

Let $\left\{\alpha_{\bar{n}}\right\}$ be the sequence generated from an arbitrary $x_{1} \in K$ by

$$
x_{n+1}=\left(1-\alpha_{n}\right) x_{n}+\alpha_{n} T x_{n}, n \geq 1
$$

Then
(i) $\lim _{n \rightarrow \infty}\left\|x_{n}-p\right\|_{\text {exists for all }} p \in F(T)$
(ii) $\liminf _{n \rightarrow \infty}\left\|x_{n}-T x_{n}\right\|=0$

(iii) $\left\{\mathrm{x}_{n}\right\}$ converges strongly to a fixed point $\mathrm{p}$ of $\mathrm{T}$ if and only if there exists a subsequence $\left\{x_{n j}\right\}_{\text {of }}\left\{x_{n}\right\}_{\text {which }}$ converges strongly top.

Let $K$ be a convex subset of $E$, and let $\left\{T_{i}\right\}_{i=1}^{N}$ be a finite family of nonexpansiveself maps of $K$.Xu and Ori (2001), introducedthe implicit iteration process.For $x_{1} \in \mathrm{K}$ and $\left\{\alpha_{n}\right\}$ in $(0,1)$, the sequence $\left\{x_{n}\right\}_{n=1}^{\infty}$ is generated as follows:

$$
\begin{aligned}
& x_{1}=\alpha_{1} x_{0}+\left(1-\alpha_{1}\right) T_{1} x_{1} \\
& x_{2}=\alpha_{2} x_{1}+\left(1-\alpha_{2}\right) T_{2} x_{2} \\
& \vdots \quad \vdots \quad \vdots \quad \vdots \quad \vdots \quad \vdots \\
& x_{N}=\alpha_{N} x_{N-1}+\left(1-\alpha_{N}\right) T_{N} x_{N} \\
& x_{N+1}=\alpha_{N+1} x_{N}+\left(1-\alpha_{N+1}\right) T_{N+1} x_{N+1}
\end{aligned}
$$

The scheme is expressed in a compact form as

$$
x_{n}=\alpha_{n} x_{n-1}+\left(1-\alpha_{n}\right) T_{n} x_{n}, n \geq 1
$$

where $T_{n}=T_{n \bmod N}$. Using this iterative process they proved weak convergence theorem for approximation of common fixed points of finite family of nonexpansive maps in Hilbert spaces (i.e. a subclass of asymptotically nonexpansive mappings for which $\|T x-T y\| \leq\|x-y\| \quad \forall x, y \in K)$

The iterative scheme (8) has been studied by many authors (see for example Xu and Ori, (2001); Sun, 2003; Osilike, 2004a, 2004b; Su and Li, 2006; Zang and Yao, 2006). Using the iteration process (8), Osilike(2004a) proved the following:

Theorem 1.2 (Osilike, 2004a). ${ }^{\text {Let } H}$ be a real Hilbert space and let $K$ be a nonempty closed convex subset of $H$ . Let $\left\{T_{i}\right\}_{i=1}^{N}$ be $N$ strictly pseudocontractive self-maps of $K$ such that $F=\bigcap_{i=1}^{N} F\left(T_{i}\right) \neq \phi$. Let $x_{o} \in K$ and let $\left\{\alpha_{n}\right\}_{n=1}^{\infty}$ be a sequence in $(0,1)$ such that $\lim _{n \rightarrow \infty} \alpha_{n}=0$. Then the sequence $\left\{x_{n}\right\}_{n=1}^{\infty}$ defined by $x_{n}=\alpha_{n} x_{n-1}+\left(1-\alpha_{n}\right) T_{n} x_{n}, \quad n \geq 1$

where $T_{n}=T_{n \bmod N}$, converges weakly to a common fixed point of the mappings $\left\{T_{i}\right\}_{i=1}^{N}$. 
Lemma 1.1 (Osilike, 2004a)

Let $E$ be a real Banach space and let $K$ be a nonempty closed convex subset of $E$. Let $\left\{T_{i}\right\}_{i=1}^{\mathrm{N}}$ be $N$ strictly pseudocontractive self-maps of $K$ such that $F=\bigcap_{i=1}^{\mathrm{N}} F\left(T_{i}\right) \neq \phi$ and let $\left\{\alpha_{n}\right\}_{n=1}^{\infty}$ be a real sequence satisfying the conditions:

$$
0<\alpha_{n}<1 \text { (ii) } \sum_{n=1}^{\infty}\left(1-\alpha_{n}\right)=\infty \text { (iii) } \sum_{n=1}^{\infty}\left(1-\alpha_{n}\right)^{2}<\infty .
$$

Let $\mathrm{x}_{1} \in \mathrm{K}$ and let $\left\{x_{n}\right\}_{n=1}^{\infty}$ be defined by

$$
x_{n}=\alpha_{n} x_{n-1}+\left(1-\alpha_{n}\right) T_{n} x_{n}, \quad n \geq 1
$$

where $T_{n}=T_{n \operatorname{modN}}$.

Then

(i) $\quad \lim _{n \rightarrow \infty}\left\|x_{n}-p\right\|$ exists for all $p \in F$

(ii) $\quad \lim _{n \rightarrow \infty} d\left(x_{n}, F\right)$ exists, where $d\left(x_{n}, F\right)=\inf _{p \in F}\left\|x_{n}-p\right\|$

(iii) $\quad \lim _{n \rightarrow \infty} \inf \left\|x_{n}-T_{n} x_{n}\right\|=0$.

Theorem 1.3 (Osilike, 2004a)

Let $E$ be a real Banach space and let $K$ be a nonempty closed convex subset of $E$. Let $\left\{T_{i}\right\}_{i=1}^{\mathrm{N}}$ be $N$ strictly pseudocontractive self-maps of $K$ such that $F=\bigcap_{i=1}^{N} F\left(T_{i}\right) \neq \phi$ and let $\left\{\alpha_{n}\right\}_{n=1}^{\infty}$ be a real sequence satisfying the conditions:

(i) $\quad 0<\alpha_{n}<1$ (ii) $\sum_{n=1}^{\infty}\left(1-\alpha_{n}\right)=\infty$ (iii) $\sum_{n=1}^{\infty}\left(1-\alpha_{n}\right)^{2}<\infty$

Let $x_{0} \in \mathrm{K}$ and let $\left\{x_{n}\right\}_{n=1}^{\infty}$ be defined by $x_{n}=\alpha_{n} x_{n-1}+\left(1-\alpha_{n}\right) T_{n} x_{n}, \quad n \geq 1$

where $T_{n}=T_{n \operatorname{modN}}$. Then $\left\{x_{n}\right\}$ converges strongly to a common fixed point of the mappings $\left\{T_{i}\right\}_{i=1}^{N}$ if and only iflim $_{n \rightarrow \infty} d\left(x_{n}, F\right)=0$, where $d\left(x_{n}, F\right)=\inf _{p \in F}\left\|x_{n}-p\right\|$.

The above results were established for strictly pseudocontractive maps in realBanach spaces using the implicit iteration scheme (8) of $\mathrm{Xu}$ and Ori. It is our purpose in this paper to extend these results from strictly pseudocontractive maps to the much more general $\phi$-demicontractive maps in real Hilbert and arbitrary real Banach spaces. Besides our results complement the results of Isiogugu(2005), extend and generalize several others in the literature (see for exampleXu and Ori, (2001, Su and Li, 2006; Zang and Yao, 2006).

In the sequel we need the following:

Lemma 1.2 (Osilike et al, 2002). Let $\left\{a_{n}\right\},\left\{b_{n}\right\}$ and $\left\{\delta_{n}\right\}$ be sequences of nonnegative real numbers satisfying the inequality $\quad a_{n+1} \leq\left(1+\delta_{n}\right) a_{n}+b_{n}, \quad n \geq 1$. If $\sum_{n=1}^{\infty} \delta_{n}<\infty$ and $\sum_{n=1}^{\infty} b_{n}<\infty$, then $\lim _{n \rightarrow \infty} a_{n}$ exists. If in addition $\left\{a_{n}\right\}_{n=1}^{\infty}$ has a subsequence which converges strongly to zero, then $\lim _{n \rightarrow \infty} a_{n}=0$.

\section{Main Results}

Theorem 2.1. Let $H$ be a real Hilbert space and let $K$ be a nonempty closed convex subset of $H$. Let $\left\{T_{i}\right\}_{i=1}^{N}$ be $N$ $\phi$-demicontractive self-maps of $\mathrm{K}$ such that $F=\bigcap_{i=1}^{N} F\left(T_{i}\right) \neq \phi$, where $F\left(T_{i}\right)=\left\{x \in K: T_{i} x=x\right\}$. Let $\left\{\alpha_{n}\right\}_{n=1}^{\infty}$ 
be a sequence in $(0,1)$ such that $\sum_{n=1}^{\infty}\left(1-\alpha_{n}\right)=\infty$, where $\alpha=\frac{1+L}{2+L}($ for $2 \alpha-1>0)$. Let $x_{1} \in K$ and let $\left\{x_{n}\right\}_{n=1}^{\infty}$ be defined by

$x_{n}=\alpha_{n} x_{n-1}+\left(1-\alpha_{n}\right) T_{n} x_{n}, \quad n \geq 1$

where $T_{n}=T_{n \bmod N}$ Then,

(i) $\quad \lim _{n \rightarrow \infty}\left\|x_{n}-p\right\|$ exists for all $p \in F \quad$ (ii) $\quad \lim _{n \rightarrow \infty} \inf \left\|x_{n}-T_{n} x_{n}\right\|=0$

(iii) $\quad\left\{x_{n}\right\}_{n=1}^{\infty}$ converges strongly to a common fixed point $\mathrm{p}$ of the mappings $\left\{T_{i}\right\}_{i=1}^{N}$ if there is a subsequence $\left\{x_{n_{j}}\right\}_{j=1}^{\infty}$ of $\left\{x_{n}\right\}_{n=1}^{\infty}$ which converges strongly to $p$.

\section{PROOF}

We shall use the following well-known result of Reinermann (1969),(see also Ishikawa (1974):

$$
\|t x+(1-t) y\|^{2}=t\|x\|^{2}+(1-t)\|y\|^{2}-t(1-t)\|x-y\|^{2}
$$

which holds for all $x, y \in H$ and $t \in[0,1]$. Let $p \in F(T)$, then using (9)and (10) we obtain

$$
\begin{aligned}
& \left\|x_{n}-p\right\|^{2}=\left\|\left(\alpha_{n} x_{n-1}+\left(1-\alpha_{n}\right) T_{n} x_{n}\right)-p\right\|^{2} \\
& =\left\|\alpha_{n}\left(x_{n-1}-p\right)+\left(1-\alpha_{n}\right)\left(T_{n} x_{n}-p\right)\right\|^{2} \\
& =a_{n}\left\|x_{n-1}-p\right\|^{2}+\left(1-a_{n}\right)\left\|T_{n} x_{n}-p\right\|^{2}-a_{n}\left(1-a_{n}\right)\left\|x_{n-1}-T_{n} x_{n}\right\|^{2} \\
& \leq a_{n}\left\|x_{n-1}-p\right\|^{2}+\left(1-a_{n}\right)\left\{\left\|x_{n}-p\right\|^{2}+\left\|x_{n}-T_{n} x_{n}\right\|^{2}-\phi\left(\left\|x_{n}-T_{n} x_{n}\right\|\right)\right\} \\
& -a_{n}\left(1-a_{n}\right)\left\|x_{n-1}-T_{n} x_{n}\right\|^{2} \\
& \left.\left\|x_{n}-p\right\|^{2} \leq \alpha_{n}\left\|x_{n-1}-p\right\|^{2}+\left(1-\alpha_{n}\right)\left\|x_{n}-p\right\|^{2}+\alpha_{n}^{2}\left\|x_{n-1}-T_{n} x_{n}\right\|^{2}-\phi\left(\left\|x_{n}-T_{n} x_{n}\right\|\right)\right\rfloor \\
& -\alpha_{n}\left(1-\alpha_{n}\right)\left\|x_{n-1}-T_{n} x_{n}\right\|^{2} \\
& =\alpha_{n}\left\|x_{n-1}-p\right\|^{2}+\left(1-\alpha_{n}\right)\left\|x_{n}-p\right\|^{2}+\alpha_{n}^{2}\left(1-\alpha_{n}\right)\left\|x_{n-1}-T_{n} x_{n}\right\|^{2} \\
& -\left(1-\alpha_{n}\right) \phi\left(\left\|x_{n}-T_{n} x_{n}\right\|\right)-\alpha_{n}\left(1-\alpha_{n}\right)\left\|x_{n-1}-T_{n} x_{n}\right\|^{2} \\
& =\alpha_{n}\left\|x_{n-1}-p\right\|^{2}+\left(1-\alpha_{n}\right)\left\|x_{n}-p\right\|^{2}-\alpha_{n}\left(1-\alpha_{n}\right)\left(1-\alpha_{n}\right)\left\|x_{n-1}-T_{n} x_{n}\right\|^{2} \\
& -\left(1-\alpha_{n}\right) \phi\left(\left\|x_{n}-T_{n} x_{n}\right\|\right) \text {. }
\end{aligned}
$$

Hence,

$$
\begin{aligned}
& \left\|x_{n}-p\right\|^{2}-\left(1-\alpha_{n}\right)\left\|x_{n}-p\right\|^{2} \leq \alpha_{n}\left\|x_{n-1}-p\right\|^{2}-\alpha_{n}\left(1-\alpha_{n}\right)^{2}\left\|x_{n-1}-T_{n} x_{n}\right\|^{2}-\left(1-\alpha_{n}\right) \phi\left(\left\|x_{n}-T_{n} x_{n}\right\|\right) \\
& {\left[1-\left(1-\alpha_{n}\right)\right]\left\|x_{n}-p\right\|^{2} \leq \alpha_{n}\left\|x_{n-1}-p\right\|^{2}-\alpha_{n}\left(1-\alpha_{n}\right)^{2}\left\|x_{n-1}-T_{n} x_{n}\right\|^{2}} \\
& -\left(1-\alpha_{n}\right) \phi\left(\left\|x_{n}-T_{n} x_{n}\right\|\right) \\
& \left\|x_{n}-p\right\|^{2} \leq\left\|x_{n-1}-p\right\|^{2}-\left(1-\alpha_{n}\right)^{2}\left\|x_{n-1}-T_{n} x_{n}\right\| \\
& -\frac{\left(1-\alpha_{n}\right)}{\alpha_{n}} \phi\left(\left\|x_{n}-T_{n} x_{n}\right\|\right) \\
& \leq\left\|x_{n-1}-p\right\|^{2}-\left(1-\alpha_{n}\right)^{2}\left\|x_{n-1}-T_{n} x_{n}\right\|^{2}-\left(1-\alpha_{n}\right) \phi\left(\left\|x_{n}-T_{n} x_{n}\right\|\right) \\
& \leq\left\|x_{n-1}-p\right\|^{2}-\left(1-\alpha_{n}\right) \phi\left(\left\|x_{n}-T_{n} x_{n}\right\|\right) \leq\left\|x_{n-1}-p\right\|^{2} \text {. }
\end{aligned}
$$

Hence $\lim _{n \rightarrow \infty}\left\|x_{n}-p\right\|$ exists, and this completes the proof of (i)

Since $\left\|x_{n}-p\right\| \leq M \forall n \geq 1$, for some $M>0$, we obtain from (11) that,

$\sum_{j=N+1}^{n}\left(1-\alpha_{j}\right) \phi\left(\left\|x_{j}-T_{j} x_{j} \quad\right\|\right) \leq \sum_{N+1}^{n}\left[\left\|x_{j-1}-\mathrm{p}\right\|^{2}-\left\|\mathrm{x}_{\mathrm{j}}-\mathrm{p}\right\|^{2}\right] \leq\left\|\mathrm{x}_{N}-\mathrm{p}\right\|^{2}<\infty$

Hence, $\quad \sum_{n=1}^{\infty}\left(1-\alpha_{n}\right) \phi\left(\left\|x_{n}-T_{n} x_{n}\right\|\right)<\infty$. 
Since $\quad \sum_{n=1}^{\infty}\left(1-\alpha_{n}\right)=\infty$, then we must have $\lim _{n \rightarrow \infty} \inf \phi\left(\left\|x_{n}-T_{n} x_{n}\right\|\right)=0$.

Since $\phi$ is strictly increasing and continuous, then $\liminf _{n \rightarrow \infty}\left\|x_{n}-T_{n} x_{n}\right\|=0$

Thus completing the proof of (ii).

Since $\left\{x_{n}\right\}_{n=1}^{\infty}$ has a subsequence $\left\{x_{n_{j}}\right\}_{j=1}^{\infty}$ which converges strongly to $p$ and $\lim _{n \rightarrow \infty}\left\|x_{n}-p\right\|$ exists, by Lemma 1.2, $\lim _{n \rightarrow \infty}\left\|x_{n}-p\right\|=0$. Thus completing the proof of Theorem 2.1.

Remark:A mapping $T$ with domain $D(T)$ and range $R(T)$ is said to be demiclosed at a point (see for exampleOsilike and Udomene, 2001) if whenever $\left\{x_{n}\right\}$ is a sequencein $D(T)$ such that $\left\{x_{n}\right\}$ converges weakly to $x \in D(T)$ and $\left\{T x_{n}\right\}$ converges strongly to $p$, then $T x=p$.If in Theorem 2.1, the iteration parameter $\left\{\alpha_{n}\right\}_{n=1}^{\infty}$ satisfies $0<\alpha_{n} \leq \alpha<1$, then $\left(1-\alpha_{n}\right) \geq 1-\alpha \quad\left(\left(1-\alpha_{n}\right)^{2} \geq(1-\alpha)^{2}\right)$ and it follows from equation(11) that $\lim _{n \rightarrow \infty}\left\|x_{n}-T_{n} x_{n}\right\|=0$. An immediate consequence of this is that if $(\mathrm{I}-\mathrm{T})$ is demiclosed at zero, then $\left\{x_{n}\right\}$ converges weakly to a common fixed point of the family $T_{i}$.

\section{Theorem 2.2}

Let $E$ be a real Banach space and let $K$ be a nonempty closed convex subset of $E$. Let $\left\{T_{i}\right\}_{i=1}^{N}$ be $N \phi$ demicontractive self-maps of $K$ such that $\lim _{n \rightarrow \infty} \alpha_{n}=1$ and the sequence $\left\{\alpha_{n}\right\}_{n=1}^{\infty}$ satisfies the conditions:
(i) $\quad 0<\alpha_{n}<1$
(ii) $\quad \sum_{n=1}^{\infty}\left(1-\alpha_{n}\right)=\infty$
(iii) $\quad \sum_{n=1}^{\infty}\left(1-\alpha_{n}\right)^{2}<\infty$

Let $\mathrm{x}_{1} \in$ Kand let $\left\{x_{n}\right\}_{n=1}^{\infty}$ be defined by $\quad x_{n}=\alpha_{n} x_{n-1}+\left(1-\alpha_{n}\right) T_{n} x_{n}, \quad n \geq 1$ where $T_{n}=T_{n \bmod N} \quad$ Then,

(i) $\quad \lim _{n \rightarrow \infty}\left\|x_{n}-p\right\|$ exists for all $p \in F$

(ii) $\quad \lim _{n \rightarrow \infty} d\left(x_{n}, F\right)$ exists, where $d\left(x_{n}, F\right)=\inf _{p \in F}\left\|x_{n}-p\right\|$

(iii) $\quad \liminf _{n \rightarrow \infty}\left\|x_{n}-T_{n} x_{n}\right\|=0$

(iv) $\quad\left\{x_{n}\right\}_{n=1}^{\infty}$ converges strongly to a fixed point of the mappings $\left\{T_{i}\right\}_{i=1}^{N}$ if there is a subsequence $\left\{x_{n_{j}}\right\}_{j=1}^{\infty}$ of $\left\{x_{n}\right\}_{n=1}^{\infty}$ which converges strongly to $p$.

\section{PROOF}

It is well known (see for example Chang ,1997) that the inequality

$$
\|x+y\|^{2} \leq\|x\|^{2}+2\langle y, j(x+y)\rangle
$$

holds for all $x, y \in E$, and $j(x-y) \in J(x-y)$.

Let $p \in F(T)$, using (9), (12) and (3) respectively, we obtain:

$$
\begin{aligned}
\left\|x_{n}-p\right\|^{2} & =\left\|\left(\alpha_{n} x_{n-1}+\left(1-\alpha_{n}\right) T_{n} x_{n}\right)-p\right\|^{2} \\
\leq & \left\|\alpha_{n}\left(x_{n-1}-p\right)\right\|^{2}+2\left\langle\left(1-\alpha_{n}\right)\left(T_{n} x_{n}-p\right), j\left(x_{n}-p\right)\right\rangle \\
& =\alpha_{n}^{2}\left\|x_{n-1}-p\right\|^{2}+2\left(1-\alpha_{n}\right)\left\langle T_{n} x_{n}-p, j\left(x_{n}-p\right)\right\rangle \\
= & \alpha_{n}^{2}\left\|x_{n-1}-p\right\|^{2}+2\left(1-\alpha_{n}\right)\left[\left\langle T_{n} x_{n}-x_{n}, j\left(x_{n}-p\right)\right\rangle+\left\langle x_{n}-p, j\left(x_{n}-p\right)\right\rangle\right] \\
\leq & \alpha_{n}^{2}\left\|x_{n-1}-p\right\|^{2}+2\left(1-\alpha_{n}\right)\left\langle T_{n} x_{n}-x_{n}, j\left(x_{n}-p\right)\right\rangle+2\left(1-\alpha_{n}\right)\left\|x_{n}-p\right\|^{2} \\
= & \alpha_{n}^{2}\left\|x_{n-1}-p\right\|^{2}-2\left(1-\alpha_{n}\right)\left\langle x_{n}-T_{n} x_{n}, j\left(x_{n}-p\right)\right\rangle+2\left(1-\alpha_{n}\right)\left\|x_{n}-p\right\|^{2}
\end{aligned}
$$


$\leq \alpha_{n}^{2}\left\|x_{n-1}-p\right\|^{2}-2\left(1-\alpha_{n}\right) \phi\left(\left\|x_{n}-T_{n} x_{n}\right\|\right)+2\left(1-\alpha_{n}\right)\left\|x_{n}-p\right\|^{2}$

Since $\lim _{n \rightarrow \infty} \alpha_{n}=1$, then there exists a positive integer $N_{1}$ such that

$\alpha_{n} \geq 1-\frac{(1-\lambda)}{2}$, for all $n \geq N_{1}, \lambda \in(0,1)$. Thus $\alpha_{n} \geq 1-2\left(1-\alpha_{n}\right), \geq \lambda$ for all $n \geq N_{1}$.

Also $\quad \lim _{n \rightarrow \infty}\left[1-2\left(1-\alpha_{n}\right)\right]=1$, so that there exists $N_{2}$ such that $1-2\left(1-\alpha_{n}\right), \leq 1+\delta$ for all $\delta>0$ and $n \geq N_{2}$. Set $D=1+\delta$ and $N=\max \left\{N_{1}, N_{2}\right\}$.

It follows from equation(13) that

$$
\begin{aligned}
\left\|x_{n}-p\right\|^{2} & \leq \frac{\alpha_{n}^{2}}{\left[1-2\left(1-\alpha_{n}\right)\right]}\left\|x_{n-1}-p\right\|^{2}-\frac{2\left(1-\alpha_{n}\right)}{\left[1-2\left(1-\alpha_{n}\right)\right]} \phi\left(\left\|x_{n}-T_{n} x_{n}\right\|\right) \\
& =\left[\frac{\left[1-2\left(1-\alpha_{n}\right)\right]+1-2 \alpha_{n}+\alpha_{n}^{2}}{\left[1-2\left(1-\alpha_{n}\right)\right]}\right]\left\|x_{n-1}-p\right\|^{2}-\left[\frac{2\left(1-\alpha_{n}\right)}{\left[1-2\left(1-\alpha_{n}\right)\right]}\right] \phi\left(\left\|x_{n}-T_{n} x_{n}\right\|\right) \\
& =\left[1+\frac{\left(1-\alpha_{n}\right)^{2}}{\left[1-2\left(1-\alpha_{n}\right)\right]}\right]\left\|x_{n-1}-p\right\|^{2}-\left[\frac{2\left(1-\alpha_{n}\right)}{\left[1-2\left(1-\alpha_{n}\right)\right]}\right] \phi\left(\left\|x_{n}-T_{n} x_{n}\right\|\right) \\
& \leq\left[1+\frac{1}{\lambda}\left(1-\alpha_{n}\right)^{2}\right]\left\|x_{n-1}-p\right\|^{2}-\frac{2}{D}\left(1-\alpha_{n}\right) \phi\left(\left\|x_{n}-T_{n} x_{n}\right\|\right) \forall n \geq N \\
& =\left[1+\sigma_{n}\right]\left\|x_{n-1}-p\right\|^{2}-\frac{2}{D}\left(1-\alpha_{n}\right) \phi\left(\left\|x_{n}-T_{n} x_{n}\right\|\right) \forall n \geq N
\end{aligned}
$$

where $\sigma_{n}=\frac{1}{\lambda}\left(1-\alpha_{n}\right)^{2}$

From condition (iii), $\sum_{n=1}^{\alpha} \sigma_{n}<\infty$, sothat it follows from Lemma 2.1 that

$\lim _{n \rightarrow \infty}\left\|x_{n}-p\right\|$ exists. This completes the proof of (i) .

Also, from equation(14) it follows that

$$
\left\|x_{n}-p\right\| \leq\left[1+\sigma_{n}\right]^{\frac{1}{2}}\left\|x_{n-1}-p\right\| \leq\left[1+\sigma_{n}\right]\left\|x_{n-1}-p\right\| .
$$

Thus, $d\left(x_{n}, F(T)\right) \leq\left[1+\sigma_{n}\right] d\left(x_{n-1}, F(T)\right)$. And again it follows from Lemma1.2 that $\lim _{n \rightarrow \infty} d\left(x_{n}, F(T)\right)$ exists, and this completes the proof of (ii).

From (14), it follows that $\left\{\left\|x_{n-1}-p\right\|\right\}_{n=1}^{\infty}$ is bounded.Let $\left\|x_{n-1}-p\right\| \leq M, \forall n \geq 1$ so that,

$$
\begin{aligned}
\frac{2}{D}\left(1-\alpha_{j}\right) \phi\left(\left\|x_{n}-T_{n} x_{n}\right\|\right) & \leq\left[1+\sigma_{n}\right]\left\|x_{n-1}-p\right\|^{2}-\left\|x_{n}-p\right\|^{2} \\
\leq & \left\|x_{n-1}-p\right\|^{2}-\left\|x_{n}-p\right\|^{2}+\sigma_{n}\left\|x_{n-1}-p\right\|^{2}
\end{aligned}
$$

Hence, $\frac{2}{D} \sum_{j=N+1}^{n}\left(1-\alpha_{j}\right) \phi\left(\left\|x_{n}-T_{j} x_{j}\right\|\right) \leq\left\|x_{N}-p\right\|^{2}+M \sum_{j=N+1}^{n} \sigma_{j}$,

and it follows that $\sum_{n=1}^{\infty}\left(1-\alpha_{n}\right) \phi\left(\left\|x_{n}-T_{n} x_{n}\right\|\right)<\infty$.

Condition (ii) implies that $\lim _{n \rightarrow \infty} \inf \phi\left(\left\|x_{n}-T_{n} x_{n}\right\|\right)=0$.Since $\phi \quad$ is strictly increasing and continuous ,then $\liminf _{n \rightarrow \infty}\left\|x_{n}-T_{n} x_{n}\right\|=0$, and this completes the proof of (iii).Again as in the proof of Theorem 2.1 (iii), since $\left\{x_{n}\right\}_{n=1}^{\infty}$ has a subsequence $\left\{x_{n_{j}}\right\}_{j=1}^{\infty}$ which converges strongly to $p$ and $\lim _{n \rightarrow \infty}\left\|x_{n}-p\right\|$ exists, by Lemma 1.2, $\lim _{n \rightarrow \infty}\left\|x_{n}-p\right\|=0$.

This completes the proof of Theorem 2.2 


\section{REFERENCES}

Browder, F. E. and Petryshyn W. V., 1967.Construction of Fixed Points of NonlinearMappings in Banach Spaces. Journal of Mathematical Analysis and Application, 20, 197-228.

Chang, S. S., 1997. Some Problems and Results in the Study of Nonlinear Analysis,Nonlinear Analysis 30, 41974208.

Chidume, C. E. and Nnoli B. V. C.,2002. A Necessary and Sufficient Condition for the Convergence of the Mann Sequence for a class of Nonlinear Operators, Bulletin of Korean Mathematical Society, 39(2), 269 - 276.

Hicks, T. L. and Kubicek, J. R., 1979. On the Mann Iterative Process in Hilbert Spaces,Journal of Mathematical Analysis and Application, 59, 498-504.

Ishikawa, I.S., 1974. Fixed Point by a New Iteration Method, Proceedings of American Mathematical Society, 149, 147 $-150$.

Isiogugu, F. O., 2005. Convergence Theorem for Fixed Points of $\phi$-DemicontractiveMappings in Banach Spaces. M.Sc. Thesis, University of Nigeria, Nsukka, Nigeria.

Mann, W. R., 1953. Mean Value Methods in Iterations, Proceedings of American Mathematical Society, 4, 506-510.

Maruster, S., 1977.The Solution by Iteration of Nonlinear Equations.Proceedings of American Mathematical Society, 66, 69-73.

Osilike, M. O., 2004a. Implicit Iteration Process for Common FixedPoints of a FiniteFamily of Strictly Pseudocontractive Maps.Journal of Mathematical Analysis and Application, 294, 73-81.

Osilike, M. O., 2004b. Implicit Iteration Process for Common FixedPoints of a FiniteFamily of Pseudocontractive Maps,Pan American Mathematical Journal, 14, 89-98.

Osilike, M. O., Aniagbosor, S. C. and Akuchu, B. G., 2002.Fixed Points ofAsymptotically Demcontractive Mapping in Arbitrary Banach Spaces.Pan American Mathematical Journal,12 (2), 77-88.

Osilike, M. O. andUdomene, A., 2001. Demiclosedness Principle and Convergence Results for Strictly Pseudocontractive Mappings of Browder-Petryshyn Type.Journal of Mathematical Analysis and Application, $25,431-445$.

Reinermann, J., 1969. UberfixpunkteKontrahievuderAbbidungen und SchwachKonvergenteTooplite-Verfhren, Arch. Math. 20, 59-64

Su, Y. and Li, S., 2006. Composite Implicit Iteration Process for a Finite Family of Strictly Pseudocontractive Maps, Journal of Mathematical Analysis and Application,320, 882-891.

Sun, Z. H., 2003. Strong Convergence of an Implicit Iteration Process for a Finite Family of Asymptotically Quasinonexpansive Mappings.Journal of Mathematical Analysis and Application,286, 351-358.

XU, H. K. and Ori, R. G.,2001.An Implicit Iteration Process for NonexpansiveMappings.Numerica Functional Analysis and Optimization, 22, 767-773.

Zang, L. and Yao, J., 2006. Implicit Iteration Scheme with Perturbed Mapping for Common Fixed Points of a Finite Family of Nonexpansive Mappings.Nonlinear Analysis, 64, 2507-2515. 